\title{
Exploring Grade Nine Geometry Spatial Mathematical Reasoning in the South African Annual National Assessment
}

\author{
Zwelithini Bongani Dhlamini ${ }^{1 *}$, Kabelo Chuene ${ }^{1}$, Kwena Masha ${ }^{2}$, Israel Kibirige ${ }^{1}$ \\ ${ }^{1}$ Department of Mathematics Science and Technology Education, University of Limpopo, SOUTH AFRICA \\ ${ }^{2}$ Center of Academic Excellence, University of Limpopo, SOUTH AFRICA
}

Received 27 December 2018 - Revised 8 March 2019 - Accepted 9 March 2019

\begin{abstract}
The purpose of this study was to explore geometry spatial mathematical reasoning in Grade nine Annual National Assessments, South Africa. Conceptual Blending was the guiding theory. Document analysis within the exploratory case study was used to explore available data, the 2014 Annual National Assessment learners' scripts $(n=1250)$. Results revealed that on average 70.5 percent of the total number of learners remembered and blended irrelevant prior knowledge not reflective to the contexts of the geometry problems. For learners who recalled the correct prior knowledge, its manipulation was either fragmented or irrelevant. The use of recalled information in wrong contexts could be due to the incorrect manipulation of the meaning of the problems. Also, responses reveal challenges on the quality of mathematics education on geometry. Therefore, the teaching and learning of geometry should focus on empowering learners with skills of recalling, blending and on manipulating problems in their contexts.
\end{abstract}

Keywords: adaptive reasoning, conceptual blending, mathematical reasoning, spatial thinking

\section{INTRODUCTION}

Geometry spatial mathematical reasoning refers to the way spaces of different shapes are conceptualised (Clements \& Battista, 1994). Geometry is the study of spatial objects' properties, the interrelatedness of its concepts, their transformations in space and a system of axioms based on mathematical representations (Lehrer, 2012). Spatial objects are defined by an interconnectedness of a set of geometry ideas (Battista, 1990). They occupy space and have a defined shape (Lehrer, 2012). The spatial objects' orientation in space and their transformations involve formulation of axioms (Lehrer, 2012) that are justified through the spatial reasoning (Clements \& Battista, 1994). The spatial reasoning is cognition of mental visuals of the spatial objects (Hegarty \& Waller, 2004). During spatial reasoning the axioms are manipulated and the meaning is conveyed in diagrammatic representations (Pittalis \& Christou, 2010). The link between geometry and spatial reasoning is important in the geometry curriculum (Clements \& Battista, 1994). The geometry curriculum is conveyed through teaching and learning of four tenets: (1) studying the spatial features of the physical world; (2) use as a tool to explain the abstract invisible mathematical concepts and connections; (3) conceptualisation, representing, and manipulation of spatial figures; and (4) the formulation of formal axioms (Usiskin, 1987).

Learners often lack the skills of tapping the properties of figures during geometric reasoning (Mabotja, Chuene, Maoto \& Kibirige, 2018). The results of their study illustrates that learners frequently require assistance from the teacher to fold back and access properties needed for proofs. Also, learners need help of blending relevant concepts when manipulating and proving axioms. In a longitudinal study, learners' representation of spatial objects was not aligned to spatial reasoning (Lehrer, 2012). These results justify the existence of challenges of spatial features, conceptions of spatial objects and formalisation of axioms. The challenges learners face pose knowledge gaps related to the second tenet (explaining and connecting) and third tenet (formulation of axioms) (Usiskin, 1987).

(C) 2019 by the authors; licensee Modestum Ltd., UK. This article is an open access article distributed under the terms and conditions of the Creative Commons Attribution License (http://creativecommons.org/licenses/by/4.0/).

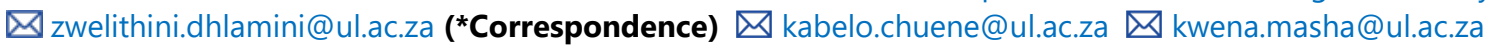




\section{Contribution of this paper to the literature}

- The findings from study add to the many national and international studies like the NAEP, NCA, NAPLAN, TIMSS, PISA, and PIRLS that provide pointers in the curricula concerning the challenges which policymakers need to address. In our case, the pointer from ANA is that there is a dearth of spatial geometric mathematical reasoning in CAPS which needs urgent attention.

- This study advances the significance of spatial thinking for success in the curricula implementation.

- The success in the spatial geometry mathematical reasoning in mathematics depends on the interpretation of the problem context. Hence, the application of spatial geometry mathematical reasoning will contribute positively to studies advocating for context learning.

Hence, this study explores geometry spatial mathematical reasoning of Grade nine learners during the South African Annual National Assessment (ANA) and asked one question. How do learners' geometry mathematical reasoning in ANA reflect on their spatial abilities? Against this backdrop of knowledge gaps, the learners' spatial abilities in geometry was established from ANA. The results from this study contribute to the paucity of data on systemic assessment in the country and also to the international literature on assessment.

The systemic assessments are administered at international, regional and national levels for different functions (Dunne et al., 2012). Ideally, data from international systemic assessments such as TIMSS evaluates the performance of a country's curriculum globally (Kellaghan et al., 2009; Resnick \& Schantz, 2017). However, at an international level the systemic assessment is conflated to rating the performance of countries (Kellaghan et al., 2009). In those ratings, South Africa has performed below the international average in TIMSS Grade eight mathematics for the past three decades (Kanjee \& Moloi, 2016). Parallel to this, the regional systemic assessments such as Southern and Eastern Africa Consortium for Monitoring Education Quality (SACMEQ) evaluates how the curriculum performs in the region (Spaull, 2016). South Africa performed below other countries in the SACMEQ Grade six mathematics (Spaull, 2016). At a national level, the ANA was introduced to gauge the performance of the curriculum, the CAPS (DBE, 2014b). At the national level, the systemic assessments are conflated to ratings of provinces and schools (Kanjee \& Moloi, 2016). As such, the result of ANA show that Grade nine learners' performance was unacceptably low in mathematics for three consecutive years, 2012, 2013 and 2014 (Pournara, Mpofu \& Sanders, 2015). The challenges were related to the format, administration, reporting and the use of the results (Bansilal, 2017; Graven \& Venkat, 2014). The quantitative data produced by the Department of Basic Education (DBE) could not address all the purposes of ANA, such as reasons regarding what learners could do or not do (Long \& Wendt, 2017).

\section{LITERATURE REVIEW}

\section{Mathematical Reasoning}

In South Africa, Ally and Christiansen (2013) found that there is a dearth of geometry mathematical reasoning in mathematics classrooms. There are two forms of mathematical reasoning. The algebraic mathematical reasoning which refers to the symbolic manipulation of quantities, representations and their relationships (Lee, 2016) and the geometry mathematical reasoning which is the figure manipulation of space, representations and their relationships (Pittalis \& Christou, 2010). The mathematical reasoning is essential for success in Primary, Secondary and Tertiary mathematics (Brodie, 2010; Pedemonte \& Balacheff, 2016). This success depends on the quality of mathematical statements, classroom conversations and written responses that are either true or false (Dhlamini \& Luneta, 2016). The statements take the form of prepositions or predicates due to their aesthetics (Eccles, 2007). A preposition denotes a mathematical statement that is true when a numerical value is assigned, and in contrast, a predicate is true for specific values and not true for other values (Eccles, 2007). Studies conducted in the USA, Sweden and Israel place great emphasis on mathematical reasoning. Despite all the efforts in those countries, there are challenges in mathematical reasoning (Jonsson, Norqvist, Liljekvist \& Lithner, 2014; Koichu \& Leron, 2015; Zandieh, Roh \& Knapp, 2014).

Learners across the spectrum of grade levels experience challenges in relation to mathematical reasoning in: 1) recalling of prior knowledge regarding definitions in spatial objects; 2) comprehending mathematical statements; 3) manipulating statements to make sense; 4) blending of mathematical concepts; and 5) validating blended mathematical statements (Otten, Bleiler-Baxter \& Engledowl, 2017). These challenges, on the one hand, emanate from misunderstanding the tenets of mathematical reasoning and on the other hand, it is from learners' inabilities to prove mathematical statements using, analogies, deductions and induction (Amir-Mofidi, Amiripour, \& Bijanzadeh, 2012; Yopp, 2015). Analogical proofs entail identifying corresponding sets of equal tenets of a spatial object to justify similarity (Amir-Mofidi et al., 2012). This type of mathematical proof reflects weak reasoning due to the 


\subsection{In $\triangle \mathrm{ABC}, \mathrm{AT} \perp \mathrm{BC}$ and $\mathrm{BT}=\mathrm{TC}$.}

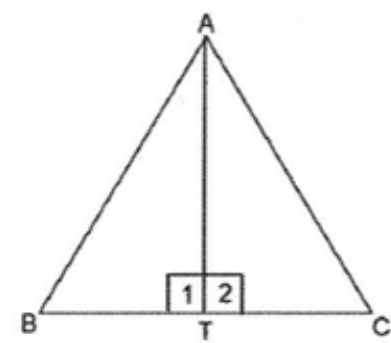

Complete the table below to prove that $\triangle \mathrm{ABT} \equiv \triangle \mathrm{ACT}$.

\begin{tabular}{|l|l|}
\hline \multicolumn{1}{|c|}{ Statement } & \multicolumn{1}{c|}{ Reason } \\
\hline In $\triangle \mathrm{ABT}$ and $\triangle \mathrm{ACT}:$ & \multicolumn{1}{|c|}{$\cdot$} \\
\hline & given \\
\hline & given $\mathrm{AT} \perp \mathrm{BC}$ \\
\hline & common \\
\hline$\therefore \triangle \mathrm{ABT} \equiv \triangle \mathrm{ACT}$ & \\
\hline
\end{tabular}

Figure 1. Grade 9 Annual National Assessment 2015 question, source (DBE, 2015: p16)

lack of rigour (Markovits \& Doyon, 2011). Deductive proofs are rigorous logical statements that learners infer to validate conclusions (Lachmy \& Koichu, 2014). A deductive proof is regarded as abstract, not easy to understand or to get hold onto its position. It disregards the reality and lacks the sense-making aspect (Lee, 2016). Inductive proof refers to the use of empirical evidence of generalising mathematical problems in specific contexts (Yopp, 2015). Hence, inductive proofs afford learners the opportunity to recall, make-sense and explain mathematical statements using the existing contexts (Pedemonte \& Balacheff, 2016).

Briefly, a coherent view postulates that mathematical reasoning depicts learners' ability to communicate mathematical statements and to connect to concepts (Brodie, 2010), which has three categories. The first category focuses on proofs that are deductive, inductive or analogical (Amir-Mofidi et al., 2012). The second category is on comprehension of mathematical meaning (Foster, 2018). The third category requires learners to validate blended mathematical statements (Lee, 2016). Otten et al. (2017) contend that teachers promote procedural rules of proof, but not the logic regarding the connection of mathematics concepts. Such a trichotomy on mathematical reasoning is problematic because it conflates mathematical reasoning and reduces it to mere proofs. This study focused on geometry mathematical reasoning.

\section{Geometry Spatial Reasoning}

In geometry, mathematical reasoning hinges on the transformation of the elements of spatial thinking between the properties of geometry figures and related concepts (Lee \& Chen, 2015). Spatial thinking as depicted by Lohman's model of three tenets: spatial visualisation (SV), spatial relations (SR) and spatial orientation (SO) (Pittalis \& Christou, 2010). The SV element refers to the ability to comprehend objects' mental visuals with coherence as they move in a variety of orientations (Munzer, Fehringer \& Kuhl, 2018). In this study, SV is the learners' ability to transform spatial intuitions to be compatible with properties of figures when proving congruency and similarity of triangles (Lee, 2016). For example, $\triangle \mathrm{ABC}$ is drawn with a perpendicular to the base (Figure 1), resulting in $\triangle \mathrm{ABT}$ and $\triangle \mathrm{ACT}$. Alongside are questions for proving congruent triangles. The $\mathrm{SV}$ in this instance relates to the ability to handle the mental schema of $\triangle \mathrm{ABT}$ and $\triangle \mathrm{ACT}$ as they appear within the orientations of $\triangle \mathrm{ABC}$ (Pittalis \& Christou, 2010). The schema should involve the following: that $\triangle \mathrm{ABT}$ and $\triangle \mathrm{ACT}$ are adjacent, sharing line AT and angle $\mathrm{T}_{1}=\mathrm{T}_{2}=90^{\circ}$. 
In contrast, the SR refers to the ability to use concepts to communicate orientations of figures in specific contexts of the geometry problems (Surtees, Apperly \& Samson, 2013). The learners' SR (Figure 1) exhibits the ability to transform the SV into the context of congruency, giving relevant statements and reasons (DBE, 2015). The SO is the learners' ability to consistently handle mental orientations of an object when making a judgement (Hegarty \& Waller, 2004). The learners' SO (Figure 1) refers to the ability to transform both the SV and SR of the figure to make a judgement that $\triangle \mathrm{ABT} \equiv \triangle \mathrm{ACT}$ (Munzer et al., 2018). All the above spatial abilities constitute geometry spatial mathematical reasoning of proving congruency. Mastery of spatial thinking has the capability of improving geometry mathematical reasoning and subsequently mathematics achievement (Munzer et al., 2018).

Lehrer (2012) worked with learners on spatial visualisation (SV) tasks that tested four aspects as follows: 1) the capacity to produce images; 2 ) memorisation of images; 3 ) identification of parts of the properties of images; and 4) transformation of images in their orientations. The results indicate that learners' skills of representing the spatial tasks (drawing) did not determine success in spatial reasoning. Actually the manipulation of the SV through the use of the tasks' properties determines success in spatial reasoning. Clements and Battista (1994) reported a series of results from empirical studies on geometry and spatial reasoning. Learners who were able to correctly transform spatial objects' orientations using relevant concept images were successful in spatial reasoning. They indicated that spatial thinking is essential for success in all layers of geometric thinking and spatial reasoning.

In most classrooms, only procedures of proofs are taught, which conflates proofs to a reproduction of theorems (Otten et al., 2017). Consequently, learners grapple when recalling and manipulating properties of spatial figures (Fujita, Kondo, Kumakura \& Kunimune, 2017; Heyd-Metzuyanim, Munter \& Greeno, 2018). Lachmy and Koichu (2014) and Komatsu, Jones, Ikeda and Narazaki (2017) found that learners justify deductive proofs using empirical evidence instead of using logic. The empirical evidence results in fragmented learners' blended mathematical reasoning which negatively affects spatial thinking (Clements \& Battista, 1994). Addressing these challenges in spatial geometry mathematical reasoning has the potential of improving learners' achievement in geometry and mathematics (Pittalis \& Christou, 2010).

\section{National and International Systemic Assessments}

Systemic mathematics assessment is a global phenomenon used to evaluate curriculum effectiveness (Dunne, Long, Graig, \& Venter, 2012; Kanjee \& Moloi, 2016). It is used to gauge and monitor the quality of education at the international, regional, and national levels (Kellaghan, Greaney \& Murray, 2009; Spaull, 2016). For international, the Trend in International Mathematics and Science Study (TIMSS) 1995, 1999, 2003, 2011 and 2015, South Africa participated in all the five years. South Africa also participates in the Progress in International Reading Literacy Study (PIRLS). In the region, South Africa participated in the Southern and Eastern Africa Consortium for Monitoring Education Quality (SAMEQ) I-IV during 1995 to1999, 2000 to 2004, 2006 to 2011, and 2012 to 2014 , respectively. During all these periods of assessment, the performance in mathematics was low (Spaull, 2016). The learners' performance in South Africa was lower than the learners from the neighbouring developing countries like Mauritius and Swaziland (Spaull, 2016). At the national level, South Africa introduced Annual National Assessment (ANA) in 2012 to gauge the performance of the Curriculum Assessment Policy Statement (CAPS) (Department of Basic Education DBE, 2014b). ANA is administered to grades three, six and nine (DBE, 2011) and the performance was worst in Grade nine for all the years: 2012, 2013, and 2014 (Kanjee \& Moloi, 2016). This low performance suggests ANA was difficult compared to tests that teachers used in classroom practice (Bansilal, 2017). The worst performance exhibited is not surprising because teachers do not teach according to CAPS (Bansilal, 2017). Consequently, the Grade nine ANA content was unfamiliar to the learners (Bansilal, 2017) and hence the low performance. Therefore, it seems there are knowledge gaps between the CAPS expectations and classroom practice (Umugiraneza, Bansilal \& North, 2018). These gaps in the systemic assessment are not only in South African CAPS, but they are also elsewhere (Dunne et al., 2012).

Systemic assessment is used to determine the curriculum efficacy (Johnson, 2017) and it highlights the challenges. In the United States of America (USA), for instance, for more than three decades the National Assessment of Educational Progress (NAEP) has highlighted a series of challenges (Hombo, 2003). These challenges include learners lack knowledge of mathematics content such as algebra and geometry (Johnson, 2017). In Australia, data from the National Assessment Program-Literacy and Numeracy (NAPLAN) revealed teaching for the test at the expense of the mathematics curricula (Klenowski \& Wyatt-Smith, 2012). Likewise, in England, data from the National Curriculum Assessment (NCA) reveal that increased teachers' workloads resulted in a compromised quality of teaching (Figueiredo, Leite \& Fernandes, 2016). The role of systemic assessment cannot be overlooked because States need to gauge the success or failure of their curricula (Hombo, 2003). A case in point is the Wales where the NCA was discontinued because of low learners' performance in Program for International Student Assessment (PISA) (Johnson, 2017). The discontinuation did not remove the challenges, but there was no indicator to alert the stakeholders to look for possible solutions and apparently, some stakeholders needed an indicator of the curriculum (NCA). Thus, the re-introduction of the NCA in Wales show the importance of the 
systemic assessment in that country (Johnson, 2017). In South Africa, the systemic assessment (ANA) assist the government to gauge the success of CAPS through testing various concepts (DBE, 2014b).

\section{Misalignment of Annual National Assessment}

The misalignment in the South African education system is apparent in three areas. First, the cognitive levels between ANA expectations and classroom assessments (Bansilal, 2017; Pournara et al., 2015). The DBE provided schools with exemplar papers (DBE, 2014a) which teachers organised their teaching strategies to cover concepts in the "exemplars papers." The use of the "exemplar papers" resulted in teachers omitting other concepts in CAPS (Graven \& Venkat, 2014). Ironically, the content of the "exemplar papers" significantly differed from that of the subsequent ANA tests (Kanjee \& Moloi, 2016) and resulted in discrepancies of learners' cognitive structures (DBE, 2014a). It is no wonder, the learners' performance in ANA was below the acceptable standard. Second, the ANA emphasis was on conceptual development, and the teachers focused on memorisation of ANA exemplars, which did not cover all the concepts in the CAPS (Graven \& Venkat, 2014). Third, there was ANA misalignment within the three years, and geometry questions were of low and different difficulty levels (Pournara et al., 2015). These areas of misalignments have the possibilities of producing data that may be misleading about the performance of CAPS (Kanjee \& Moloi, 2016). An analysis of results proved that learners performed low in geometry questions in the ANA (Bansilal, 2017) and grossly contributed to the learners' low performance in the Grade nine ANA in 2012, 2013 and 2014. Against this backdrop, we were prompted to explore learners' spatial reasoning in the ANA.

\section{Theoretical Framework}

The theoretical framework that guided this study was Conceptual Blending (CB) (Fauconnier \& Turner, 2002). The CB illustrates how the mind brings together two or more input spaces to produce the blended spaces (Fauconnier \& Turner, 2002). It has been widely used in languages, arts, physics and mathematics as mental processes of recalling learners' prior knowledge and manipulation of meaning (Sidney \& Alibali, 2015; Yoon, Thomas \& Dreyfus, 2011; Zandieh et al., 2014). In this study, the spatial object and the context of geometry problems are the two input spaces that form the blended space. During the blending, learners recall and manipulate concepts' prior knowledge from the input spaces (Eppe, Maclean, Confalonieri, Kutz, Schorlemmer, Plaza \& Kuhnberger, 2018; Gerson \& Walter, 2008). In addition, the Adaptive Reasoning (AR) concept was used to elucidate a few salient issues during the reasoning process. The AR consists of four constructs: (1) explanation of specific components of the problem; (2) logical thought that navigate through mathematical concepts; (3) justification of statements; and (4) reflection on acceptable mathematical concepts (Kilpatrick, Swafford \& Findell, 2001; Maoto, Masha \& Mokwana, 2018). The four constructs of the AR allowed us to explain learners' conceptual reasoning regarding the spatial geometry. Hence, the AR is used to capture learners' recall and manipulation processes of spatial objects in specific contexts. Thus, the AR and the CB theories were deemed suitable as lenses to understand the learners' spatial geometry mathematical reasoning.

\section{METHODS}

An exploratory case study design (Yin, 1984, Yazan, 2015) was used. Exploratory case studies explore any real life challenging phenomenon which serves as a point of interest to the researcher and that there very little is known about it (Singh, 2007). We adapted the Yinian five distinctive perspective of case study as follows: 1) the study's questions the 'how' or 'why' of the phenomenon. In our case, we answered the 'how' question which afforded us the opportunity of tapping into learners' spatial reasoning through analysing their responses to ANA geometry questions. 2) The study's intentions, that of exploring geometry spatial mathematical reasoning for problems in a context. 3) The unit of analysis, the learners' responses to questions in ANA that posed geometry spatial reasoning. 4) The logic that links data to the intentions came from the use of descriptive statistics to capture the four variables from our case, 1250 learners' scripts followed by the use of document analysis, a way of accessing learners' spatial reasoning. 5) Criteria for interpreting the findings which was guided by the AR, the $C B$ and the three tenets of spatial thinking, the SV, SR and SO (Yazan, 2015). Additionally, we considered two important aspect of the Yinian perspective of a case studies, firstly we ensured the quality of the design by ensuring reliability of the coding scheme. In this study we used three inter-raters' and their agreement of 97 percent was considered reliable. We drew from a series of descriptive statistics (Tables $1 \& 2$; Figure 2) to explain the variables. Secondly, the documents analysis was done against various theories and concepts that came from categorisation of the variable. 
Dhlamini et al. / Grade Nine Geometry Spatial Mathematical Reasoning

Table 1. Trend in learners' responses to ANA geometry questions

Learners' responses to geometry 2014 ANA question 10

\begin{tabular}{lcccccc}
\hline Learners' responses & Question 10.2 & Question 10.3.1 & Question 10.3.2 & Question 10.4.1 & Total & $\begin{array}{c}\text { Mean and standard } \\
\text { deviation }\end{array}$ \\
\hline & $\mathrm{F}(\%)$ & $\mathrm{F}(\%)$ & $\mathrm{F}(\%)$ & $\mathrm{F}(\%)$ & $\#$ & $\overline{\mathrm{x}}(\sigma)$ \\
\hline Correctly answered & $11(0.88)$ & $17(1.36)$ & $37(2.96)$ & $14(1.12)$ & 79 & $19.75(11.76)$ \\
\hline Partially answered & $149(11.92)$ & $97(7.76)$ & $194(15.52)$ & $118(9.44)$ & 558 & $139.5(42.15)$ \\
\hline Incorrectly answered & $912(72.96)$ & $962(76.96)$ & $783(62.64)$ & $868(69.44)$ & 3525 & $881.25(75.92)$ \\
\hline No response & $178(14.24)$ & $174(13.92)$ & $236(18.88)$ & $250(20)$ & 838 & $209.5(39.14)$ \\
\hline Total & $\mathbf{1 2 5 0}(\mathbf{1 0 0})$ & $\mathbf{1 2 5 0}(\mathbf{1 0 0})$ & $\mathbf{1 2 5 0 ( 1 0 0 )}$ & $\mathbf{1 2 5 0 ( 1 0 0 )}$ & $\mathbf{5 0 0 0}$ & - \\
\hline
\end{tabular}

Table 2. Learners' responses dispersion from the mean

\begin{tabular}{lcccccc}
\hline \multicolumn{7}{c}{ Mean deviations for learners' responses to the 2014 ANA question 10 } \\
\hline Learners' responses & Question 10.2 & Question $\mathbf{1 0 . 3 . 1}$ & Question 10.3.2 & Question 10.4.1 & $\begin{array}{c}\text { Total } \\
|\#|\end{array}$ & Mean deviation \\
\hline Correctly answered & -8.75 & -2.75 & 17.25 & 5.25 & 34 & 8.5 \\
\hline Partially answered & 9.5 & -42.5 & 54.5 & -21.5 & 128 & 32 \\
\hline Incorrectly answered & 30.75 & 80.75 & -98.25 & -13.25 & 223 & 55.75 \\
\hline No response & -31.5 & -35.5 & 26.5 & 40.5 & 134 & 33.5 \\
\hline
\end{tabular}

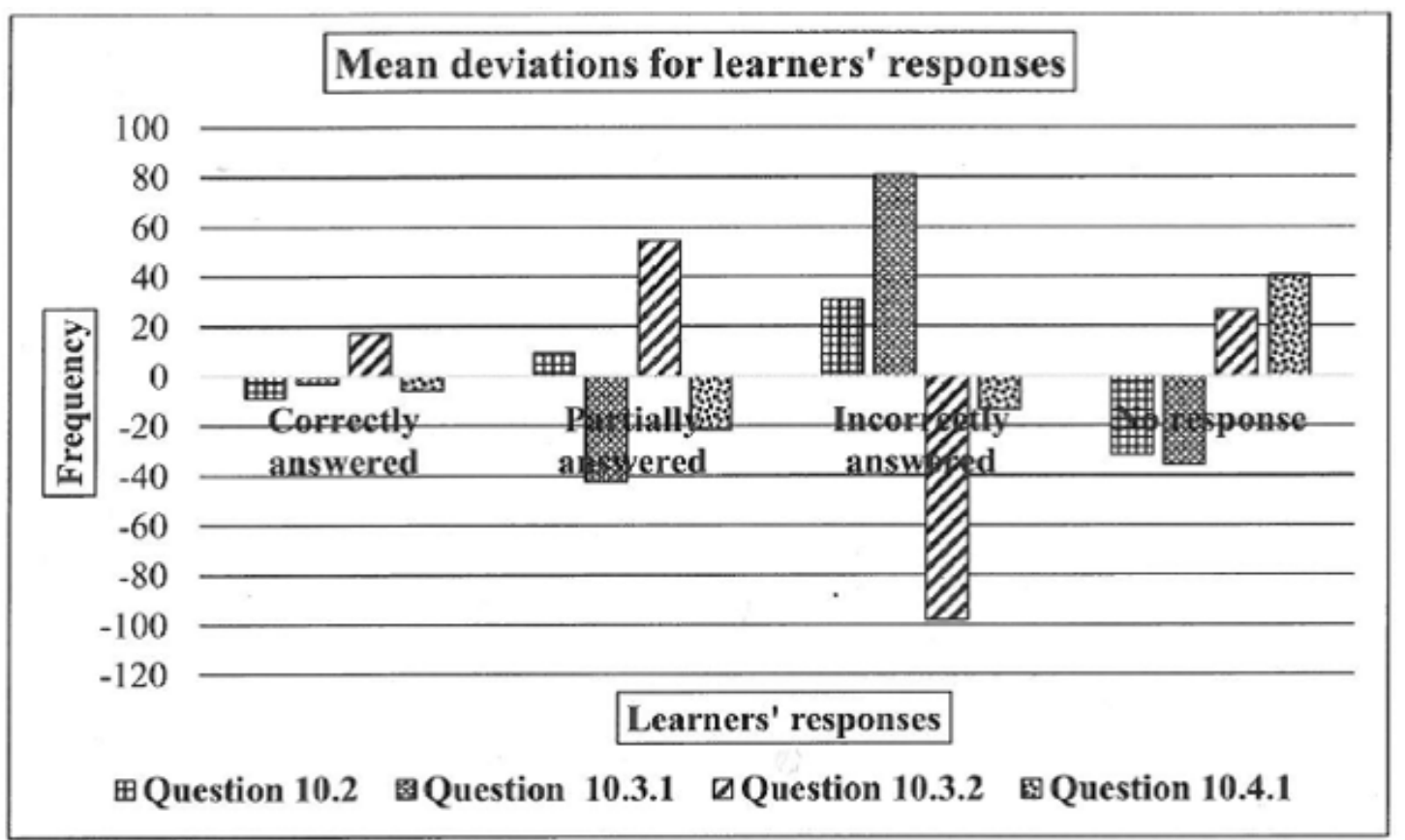

Figure 2. Variations of learners' responses to geometry questions

\section{Sampling}

This research was from a comprehensive study conducted by the first author under the supervision of the other three authors. The data came from document analysis of purposively sampled ANA 2014 Grade nine mathematics, $\mathrm{n}=1250$ learners' scripts. At first, the researcher conveniently sampled nine schools from the Capricorn District, Limpopo Province, South Africa due to their location and voluntary access provided by the school principals. Additionally, four Geometry questions were purposefully selected from question ten, because we conceived that they used spatial objects to coherently question spatial reasoning and geometry. Such coherence came from proofs of congruency and similarity that required justifications. Finally, we purposively sampled the Limpopo Province due to below average performance in Grade nine mathematics ANA in the three consecutive years, 2012, 2013 and 2014. 
Table 3. Explanation of learners' mathematical reasoning to the four parts of question 10

\begin{tabular}{|c|c|c|c|}
\hline \multicolumn{4}{|c|}{ Mathematical Reasoning analysis key for ANA 2014 geometry learners' responses } \\
\hline MR10.2A & MR10.2B & MR10.2C & MR10.2D \\
\hline $\begin{array}{l}\text { No response; blank } \\
\text { space left in the learners' } \\
\text { script. }\end{array}$ & $\begin{array}{l}\text { Incorrect response; recalled and } \\
\text { blended prior knowledge is not } \\
\text { relevant to the geometry spatial } \\
\text { reasoning posed by the problem. }\end{array}$ & $\begin{array}{l}\text { Partially answered; blended } \\
\text { response either did not show } \\
\text { with reasons, equal radii, } \\
\text { common side, equal right angles } \\
\text { or conclusion. }\end{array}$ & $\begin{array}{l}\text { Correctly answered; blended } \\
\text { response shows with reasons } \\
\text { equal radii, common side, equal } \\
\text { right angles and conclusion. }\end{array}$ \\
\hline MR10.3.1A & MR10.3.1B & MR10.3.1C & MR10.3.1D \\
\hline $\begin{array}{l}\text { No response; blank } \\
\text { space left on the } \\
\text { learners' script. }\end{array}$ & $\begin{array}{l}\text { Incorrect response; recalled and } \\
\text { blended prior knowledge is not } \\
\text { relevant to the geometry spatial } \\
\text { reasoning posed by the problem. }\end{array}$ & $\begin{array}{l}\text { Partially answered; blended } \\
\text { response either did not } \\
\text { show } B F=C E \text { or } B F+F C= \\
C E+F E \text { or did not show } B C= \\
E F\end{array}$ & $\begin{array}{l}\text { Correctly answered; blended } \\
\text { response shows } B F=C E \text { as } \\
\text { given and } B F+F C=C E+F E \\
\text { resulting in } B C=E F\end{array}$ \\
\hline MR10.3.2A & M10.3.2B & MR10.3.2C & MR10.3.2D \\
\hline $\begin{array}{l}\text { No response; blank } \\
\text { space left on the } \\
\text { learners' script }\end{array}$ & $\begin{array}{l}\text { Incorrect response; recalled and } \\
\text { blended prior knowledge is not } \\
\text { relevant to the geometry spatial } \\
\text { reasoning posed by the problem. }\end{array}$ & $\begin{array}{l}\text { Partially answered; blended } \\
\text { response, either did not show } 2 \\
\text { pairs of equal sides or that } B C= \\
E F \text { is already proved }\end{array}$ & $\begin{array}{l}\text { Correctly answered; blended } \\
\text { response shows } 2 \text { pairs of equal } \\
\text { given sides, and show } B C=E F \\
\text { as proved. }\end{array}$ \\
\hline MR10.4.1A & MR10.4.1B & MR10.4.1C & MR10.4.1D \\
\hline $\begin{array}{l}\text { No response; blank } \\
\text { space left on the } \\
\text { learners' script. }\end{array}$ & $\begin{array}{l}\text { Incorrect response; recalled and } \\
\text { blended prior knowledge is not } \\
\text { relevant to the geometry spatial } \\
\text { reasoning posed by the problem. }\end{array}$ & $\begin{array}{l}\text { Partially answered; blended } \\
\text { response either, incorrect } \\
\text { reasons, or correct pair of equal } \\
\text { angles. }\end{array}$ & $\begin{array}{l}\text { Correctly answered; blended } \\
\text { response shows; } \hat{A} \text { common, } \hat{B}= \\
\hat{C} \text { with reason 'given' and } \widehat{D_{1}}=\widehat{E_{1}} \\
\text { reason, 'sum of interior angles of } \\
\text { a triangle equals } 180^{\circ} \text { which } \\
\text { proves for similarity. }\end{array}$ \\
\hline
\end{tabular}

\section{Procedures}

This study used the available data from the 2014 ANA scripts and analysed them in various ways. The learners' responses were categorised into four variables as follows: 1) no response, undocumented blended spatial geometry mathematical reasoning. This variable came from uncertainty why learners skipped the questions, either lack of the mathematical reasoning or limited time allocated to the test against the difficulty level. The use of CB and spatial thinking allowed the raters to conceptualise how learners blended spatial mathematical reasoning in the context of the geometry problem. 2) Incorrectly answered, irrelevant blended spatial geometry mathematical reasoning. The sampled geometry problems had a context (figure) and questions related to geometry concepts. From the responses, learners recalled geometry concepts that were irrelevant to the context of the geometry problems, hence classified in this category. 3) Partially answered, fragmented blended spatial geometry mathematical reasoning. Learners who were classified in this variable recalled the relevant geometry concepts and the manipulation was irrelevant to the context of the geometric problem. 4) Correctly answered, appropriately blended spatial geometry mathematical reasoning. Learners who were classified in this variable appropriately recalled and manipulated geometry concepts that were relevant to the context of the geometric problems.

Three experienced mathematics educators rated the learners' responses using the marking guideline: the CB theory; the concept AR; and the literature on spatial thinking. The raters agreed on a coding scheme (Table 3). Where there were disagreements, the raters had to critically apply the marking guidelines and the CB theory to capture the blended spatial geometry mathematical reasoning. In one case, Figure 6, where the learners' response was wrongly marked, one rater noted the discrepancy after the other two raters had classified it as 'incorrectly answered.' The percent agreement of 97 percent reached, which is above the acceptable minimum value of 75 percent (McHugh, 2012). The frequencies of the agreed ratings are shown in Table 1.

Two methods used, the generation of descriptive statistics and document analysis for the purposes of triangulation to ensure credibility of findings (Creswell, 2014). The descriptive statistics, standard deviations and mean deviations were generated from how the learners responded to the geometry questions. Standard deviations measured the variance of the four variables from the mean (Creswell, 2014), while mean deviations showed discrepancies of the four variables (Gorard, 2005). Subsequently, the document analysis conducted on the learners' responses were coded using axial coding, to capture mathematical reasoning that learners exhibited (Gibbs, 2012) and subsequently, four themes emerged. For access, permission to conduct the study was sought from the DBE in the Limpopo Province in South Africa. 


\section{RESULTS}

In general, the results indicate that most learners incorrectly answered geometry questions in the 2014 Grade nine mathematics ANA. They recalled, manipulated and blended spatial geometry mathematical reasoning that was not relevant to the context of the problems. Those who partially answered, recalled relevant prior knowledge, however, the blended spatial mathematical reasoning was fragmented due to incorrect manipulation that was inconsistent with the context of the problem. The few learners who blended appropriate spatial geometry mathematical reasoning recalled correctly prior knowledge, and their manipulations were consistent in the context of the problems.

\section{How Learners Responded to Spatial Geometry Mathematical Reasoning}

The data in Table 1 indicates trends on how learners answered the geometry problems. The variable incorrectly answered had the highest frequencies, mean and standard deviation followed by the no response, but third regarding standard deviation. The variable partially answered shows third lowest frequencies, percentages and means, and second regarding standard deviation. Lastly, the variable correctly answered depicts lowest frequencies, percentages, means and standard deviations.

The data in Table 2 shows the mean deviations of learners' responses. The variable incorrectly answered had positive mean deviations for questions 10.2 and 10.3.1, and negative mean deviations for question 10.3.2 and question 10.4.1. In contrast, the variable no response mean deviation was positive for questions 10.3.2 and 10.4.1 and negative for question 10.2 and question 10.3.1. In the variable partially answered the mean deviation was positive for questions 10.2 and 10.3.2, and negative for question 10.3.1 and question 10.4.1. Lastly, in the variable correctly answered the mean deviation was positive for questions 10.3.1 and 10.4.1 and negative for questions 10.2 and 10.3.2.

The data in Table 2 was used to generate the descriptive statistics (Figure 2), of mean deviations with direction for learners' responses. This illustration visualises the variances shown in Table 2.

Table 3 outlines the coding of mathematical reasoning as blended by learners when manipulating the meaning of the geometry problems. The codes in the first column captured questions where learners left blank spaces. The codes in the second column captured mathematical reasoning that was irrelevant to the context of the geometry problems. The codes in the third column captured erroneously blended mathematical reasoning. Lastly, the codes in the fourth column captured mathematical reasoning that was relevant to the geometry problems.

Four themes emerged from the axial coding of learners' responses: Theme 1, undocumented blended spatial geometry mathematical reasoning; Theme 2; irrelevant blended spatial geometry mathematical reasoning, Theme 3; fragmented blended spatial geometry mathematical reasoning, and Theme 4; appropriately blended spatial geometry mathematical reasoning. These themes are explored further below using the learners' responses.

\section{Undocumented Blended Spatial Geometry Mathematical Reasoning}

In Figure 3 is a learners' response to question 10.2 for the Grade nine mathematics 2014 ANA. The response was coded as MR10.2A, one of 178 classified in the variable no response. The response posits that the learner left a blank space and the marker wrote question marks. From Figure 3 the meaning of the question marks is not clear. We could not ascertain the spatial thinking, SV, SR and SV that the learner either mentally recalled or manipulated to respond to the demands of the problem (Kilpatrick et al., 2001; Yoon et al., 2011). We infer that there is some blended geometry mathematical reasoning that was not documented by learners (Gerson \& Walter, 2008). This blended geometry mathematical reasoning is caused by learners' doubting their prior knowledge which is attributed to failure to make sense of the context (Sidney \& Alibali, 2015). Hence, teachers who marked the ANA scripts could not ascertain the blended spatial geometry mathematical reasoning. 
10.2 In the given figure, $P$ and $T$ are points on a circle with centre $M . N$ is a point on a chord $P T$ such that $M N \perp P T$.

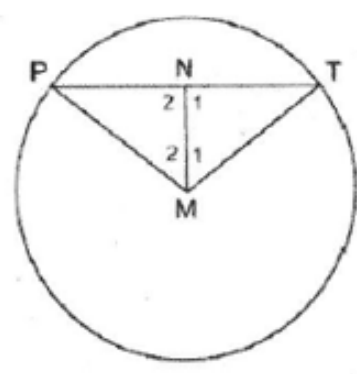

Prove that $P N=N T$.

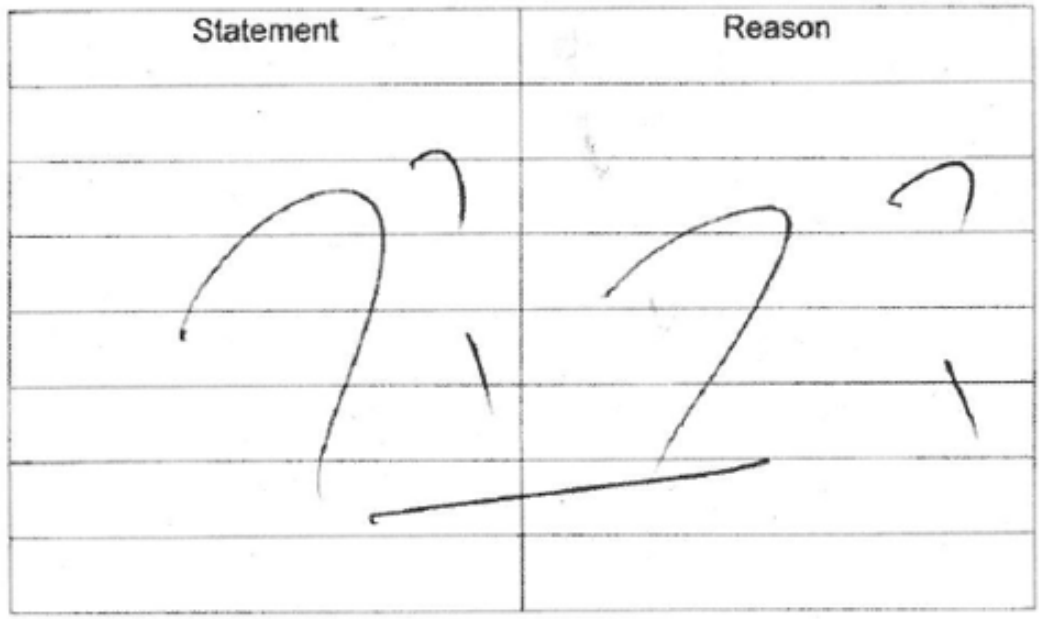

Figure 3. Learners' response to question 10.2 coded (MR10.2A)

\section{Irrelevant Blended Spatial Geometry Mathematical Reasoning}

Figure 4 is a learners' response to question 10.4.1 for the 2014 Grade nine mathematics ANA. The response was coded MR10.4.1B, one of 868 classified in the variable incorrectly answered. The posed problem required learners to recall the concept of similarity, which is, identify three equal corresponding angles in two triangles, give reasons for equality. Such thinking processes have to be guided by the spatial properties of the provided figure. From Figure 4, the SV is the learners' ability to handle the mental schema of $\triangle \mathrm{ABD}$ and $\triangle \mathrm{ACE}$ in relation to the concept of similarity and as these triangles appear within the orientations of the figure ACFB. However, the learner manipulated inappropriate procedure that is not related to proving similarity which justifies lack of SV. Correspondingly, the learner transformed irrelevant SV into the context of similarity which subsequently resulted in SR as follows: 1) incorrect manipulation, using length of sides to prove similarity instead of using given properties of the triangles, 2) using properties of triangles such as; interior angles of a triangle sum up to $180^{\circ}$ to incorrectly prove similarity, and 3) the use of invalid reasons to justify given statements, e.g. 'parallel to each other and sum of angles of a triangle'. Finally, the learner could not reach a conclusion that $\triangle \mathrm{ABD}$ and $\triangle \mathrm{ACE}$ are similar using the irrelevant SV and SR, justifying lack of SO. 
10.4

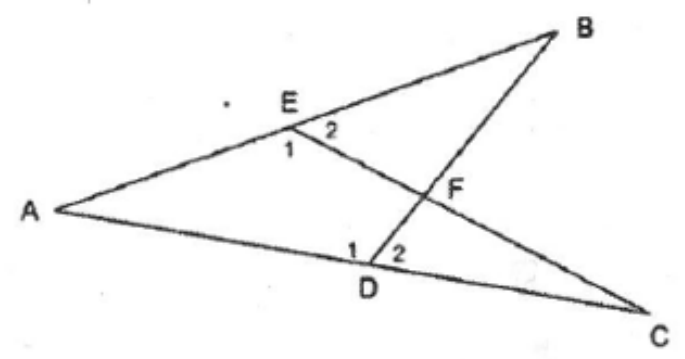

In the figure, $B=C, A D=9 \mathrm{~cm}, A E=7 \mathrm{~cm}$ and $C E=21 \mathrm{~cm}$.

10.4.1 Prove that $\triangle A B D \| \triangle A C E$.

\begin{tabular}{|l|l|}
\hline \multicolumn{1}{|c|}{ Statement } \\
$\triangle A B D 111 \triangle A C E$ \\
$\triangle A B D=9 \mathrm{~cm}=27 \mathrm{~cm}=30 \mathrm{~cm}$ & Parallel to each other \\
\hline$\triangle A C E=9 \mathrm{~cm}+7 \mathrm{~cm}+21 \mathrm{~cm}=$ & \\
\hline $37 \mathrm{~cm}$ & Sum grangles of atrangle \\
\hline & \\
\hline
\end{tabular}

Figure 4. Learners' responses to question 10.4.1 coded (MR10.4.1B)

\section{Fragmented Blended Spatial Geometry Mathematical Reasoning}

Figure 5 is a learners' response to question 10.3.2 for the 2014 Grade nine mathematics ANA. The response was coded MR10.3.2C, one of 194 classified in the variable partially answered. From the response, we establish that the learner recalled relevant prior knowledge required to prove congruency. That is, identify with reasons, three equal sides or angles with reasons from corresponding triangles although the learner identified four, and three pairs of corresponding sides and one pair of angles. Such prior knowledge constitutes the SV, the ability to handle $\triangle \mathrm{ABC} \equiv \triangle \mathrm{DEF}$ as they appear within the orientations of the figure ABFDEC. Unfortunately, when manipulating meaning, some specific components of the problem were not relevant which resulted in irrelevant SR, i.e. the first two reasons denoted by 'proven' were incorrect, and the relevant statements regarding the context of the problem were 'given'. Correspondingly, the statement and reason recalled by the learner, 'BF $=C E$ proven and $C_{1}=F_{1}$ common' was invalid and not necessary, ideally three valid statements are required to prove for congruency. Finally, the learner used fragmented blended $\mathrm{SV}$ and $\mathrm{SR}$ to make a judgement that $\triangle \mathrm{ABC} \equiv \triangle \mathrm{DEF}$, an obvious lack of the SO. 
10.3.2 Prove that $\triangle A B C \equiv \triangle D E F$.

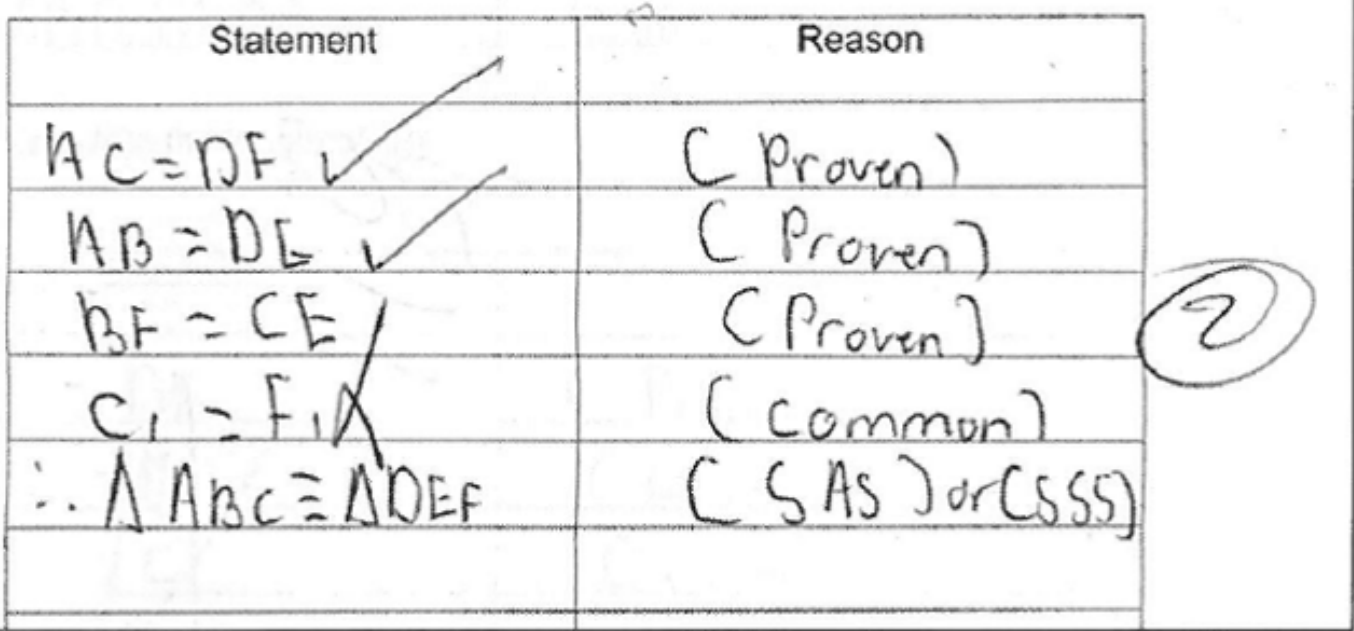

Figure 5. Learners' responses to question 10.3.2 coded (MR10.3.2C)

10.3

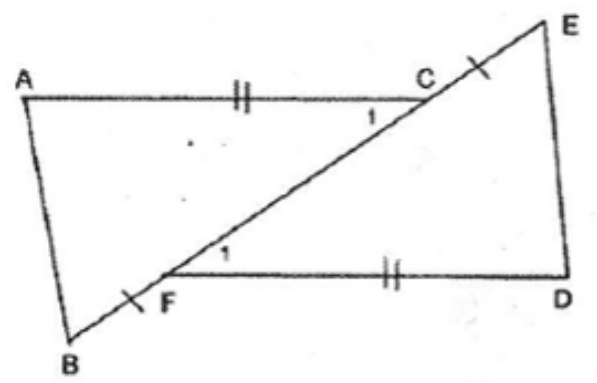

In the above diagram, $A C=D F, A B=D E$ and $B F=C E$.

10.3.1 Prove that $B C=E F$.

\begin{tabular}{|l|l|}
\hline \multicolumn{1}{|c|}{ Statement } & \multicolumn{1}{c|}{ Reason } \\
\hline$A C=\Delta F$ & (Proven) \\
$A B=E \Delta$ & ( " ) \\
\hline$B C=E F$ & (SAS or (SSS) \\
\hline
\end{tabular}

(2)

Figure 6. Learners' responses to question 10.3.1 coded (MR10.3.1C)

Another response that was in this category appears in Figure 6, one of 194 coded MR10.3.1C. From the response, we discover that the learners' explanation of the basic concept of congruency, the SV was relevant, e.g. $A C=$ $D F ; A B=E F ;$ and $B C=E F$. Noticeably, the learner manipulated an irrelevant component of the problem, $B C=E F$ instead of $B F+F C=C E+F C$. However, when navigating through the concept of congruency, the learner provided invalid reasons for the statements, such as, "proven" and "SAS or SSS" justifying irrelevant SR. The learner could not transform and reflect on the SV and SR into a sound judgement that BC $=\mathrm{EF}$, another obvious lack of SO. Unfortunately, the marker could not credit the relevant statements which justifies inconsistency in the marking processes of ANA. 
10.2 In the given figure, $P$ and $T$ are points on a circle with centre $M . N$ is a point on a chord $P T$ such that $M N \perp P T$.

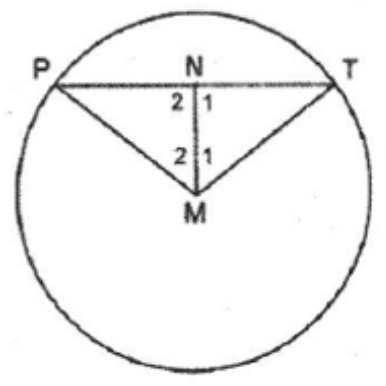

Prove that $P N=N T$.

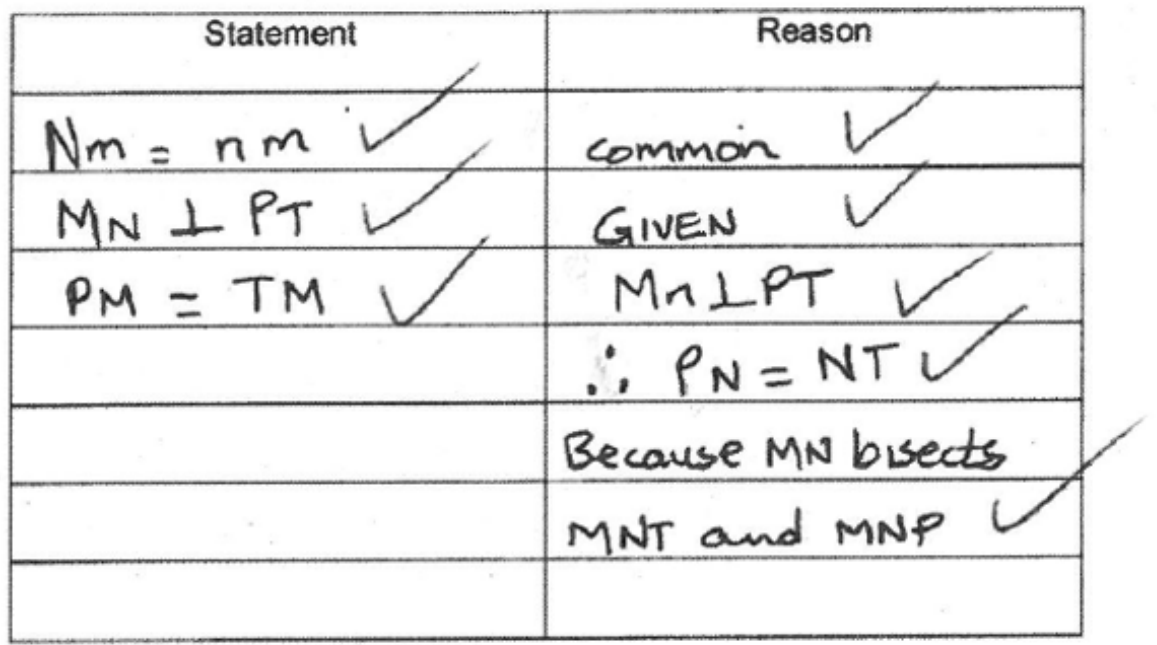

Figure 7. Learners' responses to question 10.2 coded (MR10.2D)

\section{Appropriately Blended Spatial Geometry Mathematical Reasoning}

Figure 7 is a learners' response to question 10.2, for Grade nine mathematics in 2014 ANA. The response was coded MR10.2D, one of 11 classified in the variable correctly answered. The problem uses a figure with two triangles drawn from the centre of a circle. Learners were required to reflect on two radii in the bigger triangle (PMT), which makes it an isosceles triangle. Such reflection required learners to handle the concepts of radii as they appeared within the orientations of the circle and the triangles which constituted the SV. For the SR, the question required proving that $M N \perp P T$ required that the perpendicular bisector, $\mathrm{MN}$, bisects the base, PT. Since they are in a straight line, for equality, the angles must be $90^{\circ}$. Finally, the learner transformed correctly both the SV and SR to justify and reflect that PN and TN are equal corresponding sides of congruent triangles to show mastery of the SO.

\section{DISCUSSION}

The purpose was to explore geometry spatial mathematical reasoning in the South African Grade nine in 2014 ANA. The Conceptual Blending (CB) was the theoretical framework underpinning the learners' geometry spatial mathematical reasoning. The CB merged learners' thinking on the properties of figures and their contexts to blend varieties of geometry mathematical reasoning. The Adaptive Reasoning (AR) was used as a concept to understand the learners' coherent reasoning dealing with explanations, logical thoughts, justifications, and reflections. During this process the three components of spatial thinking: the SV, SR and SO by the Lohman's model assisted in understanding learners' spatial reasoning as follows: 1) the SV guided the study on how learners recalled prior 
knowledge that transformed properties of objects within their orientations; 2) the SR allowed us to identify how learners manipulated the SV within the context of congruency and similarity into the blended spatial reasoning; and 3) the use of the SO assisted in identifying how learners transformed SV and SR in their responses to make judgements.

The results revealed that: 1) there was undocumented Blended Spatial Geometry Mathematical Reasoning; 2) bulk of learners recalled and manipulated irrelevant blended spatial geometry mathematical reasoning; 3) some learners had fragmented blended spatial geometry mathematical reasoning which they incorrectly used to manipulate the context; and 4) a few learners correctly manipulated prior knowledge to appropriately blend spatial geometry mathematical reasoning. These results indicate that spatial ability is key to success in geometry and confirm other results (Pittalis \& Christou, 2010). Hence, improving spatial abilities is more likely to enhance learners' geometry mathematical reasoning provided teachers to receive professional development. Furthermore, this study confirms the study of Umugiraneza et al. (2018) who contend that most teachers in South Africa grapple interpreting and implementing the CAPS.

In instances where learners' scripts had empty spaces, using the $\mathrm{CB}$, it was interpreted as "undocumented blended spatial geometry mathematical reasoning." It can be assumed that there was some form of blended spatial reasoning. However, this opens the opportunity for further study in this discourse following additional methods. The irrelevantly blended spatial mathematical reasoning was prevalent in the bulk of learners in the ANA. This large number of learners with inappropriate blended spatial mathematical reasoning is an indicator that CAPS is not performing well in geometry and the range of not achieving learners and achieving learners is great (Table 1). The high standard deviations differences show that learners mathematical reasoning varied (Gorard, 2005) for the incorrectly answered questions suggesting substantial challenges with the geometry questions. It is not surprising that mathematical reasoning challenges are identified in this study because they have been previously reported in some South African classrooms (Ally \& Christiansen, 2013). Also, the data highlight variances with the mean blended spatial geometry mathematical reasoning and are useful to identify questions that were challenging to learners (Munzer et al., 2018). In the context of ANA, the results inform policymakers about the prevalent discrepancies in learners' responses to each question (Kanjee \& Moloi, 2016).

The most disturbing results were the irrelevant blended spatial geometry mathematical reasoning exhibited in the learners' responses, and this suggests that learners failed to transform all the three tenets of spatial thinking related to the context (Figure 4). First, the irrelevant SV for recalling of properties or concepts, the learner used length instead of corresponding sides or angles. This recall of irrelevant concepts is considered by Munzer et al. (2018) as the lack of SV. Second, the manipulating of irrelevant properties and concepts were consistent with the findings of Hegarty and Walter (2004) which depict the lack of SR. The learner manipulated length instead of corresponding sides. Third, the use of irrelevant information when making judgements on congruency or similarity indicate that learners lacked SO which is in line with the results from Surtees et al. (2013). For example, the use of length could not warrant justification for similarity. These findings concur with Munzer et al. (2018) that failure to handle the SV affects all other related elements of spatial reasoning. Consequently, all components of AR were irrelevant (Kilpatrick et al., 2001). Similarly, using the $C B$, the recalled prior knowledge and manipulation (Fauconnier \& Tuner, 2002) were inappropriate to the input spaces, the properties of spatial objects and the context. Maoto et al. (2018) identified that such irrelevant blended geometry mathematical reasoning emanates from the unidirectional approach of teaching spatial geometry mathematical reasoning. These results suggest that teachers need training in accessing and addressing learners' spatial thinking that is inappropriate to the contexts of specified problems.

A few results revealed that learners recalled relevant prior knowledge which they incorrectly used to manipulate the context. The failure to contextualise the prior knowledge was as a result of inconsistency in the blended spatial geometry thinking. Consequently, the erroneous manipulation led to the learners' defective spatial thinking (Figure 5). First, the learner used corresponding sides, a concept for proving congruency which Fujita et al. (2017) regarded as relevant SV. Second, the learner provided three matching sides, in which one was incorrect and an erroneously matched pair of angles that made the SR inappropriate (Foster, 2018). Third, the use of erroneous SR to make an invalid judgment justifies the lack of SO (Pittalis \& Christou, 2010). The results indicate that the AR and CB were defective resulting in fragmented spatial geometry mathematical reasoning (Zandieh et al., 2014). Hence the need to harness the learners' manipulation of prior knowledge in geometry is justified.

Furthermore, it is shocking to learn from the results that very few learners recalled and manipulated prior knowledge that was relevant to the context. All elements of spatial thinking were relevant to the context of the problem (Figure 7). These results justify the mastery of all the components of mathematical reasoning and the CB relative to the context (Kilpatrick et al., 2001; Fauconnier \& Turner, 2002). They also justify mastery of all components of spatial geometry mathematical reasoning concerning the context (Munzer et al., 2018). Our observation here is, a few learners are capable of exhibiting relevant spatial thinking irrespective of teaching geometry not according to CAPS (Bansilal, 2017). 


\section{CONCLUSION}

This study contributes to the discourse of geometry spatial mathematical reasoning through the exploration of learners' responses in the Annual National Assessment (ANA). The use of the concept of Adaptive Reasoning (AR), the theory of conceptual blending (CB) and the literature from spatial thinking unveiled salient challenges that learners experience in implementing CAPS. The spatial reasoning has the potential of empowering learners with skills of transforming geometry orientations of figures into contexts of problems and make informed judgements. The CB theory enabled us to track learners' explanations, manipulations, justifications and reflections on geometry concepts in contexts through their blended spatial reasoning. The implications of these results will provide policymakers with worthwhile data to reassess the use of ANA for improvements and add to the literature.

The research question was as follows: how do learners' geometry mathematical reasoning in ANA reflect on their spatial abilities? Most learners recalled and manipulated irrelevant spatial geometry mathematical reasoning. They retrieved irrelevant mental visuals, communicated flawed spatial orientations, and this resulted in inappropriate judgements that were not applicable to the context of the problems. The bulk of learners' responses in this category validates the existence of challenges in the teaching and learning of geometry. Correspondingly, learners who recalled the relevant spatial orientations of the problems, and had challenges, struggled to efficiently manipulate certain orientations of the figures resulting in fragmented spatial geometry mathematical reasoning. Also, the marking that was inconsistent with the context of the problems filtered into ANA results, producing misleading data for such systemic assessment. Finally, the handful of learners who correctly blended and manipulated appropriate blended spatial geometry mathematical reasoning signalled the existence of teaching of relevant concepts of geometry. The results justified concerns on the learners' blending of spatial geometry mathematical reasoning. This blending has the potential to improve achievement in geometry and mathematics. The literature review indicated the shortage of studies on what learners can or cannot do in systemic assessment. We, therefore, recommend transforming curriculum that focuses on learners spatial abilities.

\section{Limitations to the Study}

There are three limitations to the study. 1) The sample of the study was small covering schools in Limpopo, one of the nine provinces, in South Africa and little is known from the other eight provinces. 2) The study was restricted to Grade nine ANA and did not include Grades three and six. 3) The study used learners' scripts to track their geometry spatial reasoning one year after they had left Grade nine and it was not possible to interview such learners, in instances where there were unanswered questions (empty space in the script), to identify their geometry spatial mathematical reasoning. Therefore, generalising from this study should be exercised with vigilance. Future studies should track learners' geometry spatial mathematical reasoning in Grade three, six, and nine for all the nine provinces in the country. Furthermore, those studies should include personal interviews to identify reasons why learners left some questions unanswered.

\section{ACKNOWLEDGEMENTS}

1. There is no conflict of interest attached among the authors of this article. This work emanates from the first authors' $\mathrm{PhD}$ thesis. Other authors were the supervisors of the thesis and are affiliated to University of Limpopo.

2. This research was partly funded by the National Research Foundation and views expressed here are not those of the funder.

\section{REFERENCES}

Ally, N., \& Christiansen, M. (2013). Opportunities to develop mathematical proficiency in Grade 6 mathematics classroom in Kwazulu-Natal. Perspectives in Education, 31(3), 106-121. Retrieved from http:/ / perspectivesin-education.com

Amir-Mofidi, S., Amiripour, P., \& Bijan-zadeh, M. (2012). Instruction of mathematical concepts through analogical reasoning skills. Indian Journal of Science and Technology, 5(6), 2916-2922. https:/ / doi.org/10.17485/ijst/2012/v5i6/30485

Bansilal, S. (2017). The Difficulty level of a national assessment of Grade 9 mathematics: The case of five schools. South African Journal of Childhood Education, 7(1), 1-8. https:/ / doi.org/10.4102/ sajce.v7i1.412

Battista, M. T. (1990). Spatial visualisation and gender differences in high school geometry. Journal for Research in Mathematics Education, 21(1), 47-60. https:/ / doi.org/10.2307/749456 
Brodie, K. (2010). Teaching Mathematical Reasoning in secondary classrooms, 1st Edition. Dordrecht, Springer. https:// doi.org/10.1007/978-0-387-09742-8

Clements, D. H., \& Battista, M. T. (1992). Geometry and spatial reasoning. Handbook of research on mathematics teaching and learning, 420-464.

Creswell, J. (2014). Educational research: Planning, conducting and evaluating quantitative and qualitative research, $4^{\text {th }}$ Edition. New Jersey, Pearsons Education.

Department of Basic Education (DBE). (2011). Curriculum and assessment policy statements Grades 7-9. Pretoria. Retrieved from http:/ / www.education.gov.za

DBE. (2014a). The annual national assessment of 2014 diagnostic report intermediate and senior phases mathematics. Pretoria. Retrieved from http:/ / www.education.gov.za

DBE. (2014b). Report on the annual national assessment of 2014: Grades 1 to $6 \mathcal{E}$ 9, Pretoria. Retrieved from http:/ / www.education.gov.za

DBE. (2015). Annual National Assessment 2015 Grade 9 Mathematics Test, Pretoria. Retrieved from www.education.gov.za

Dhlamini, Z. B., \& Luneta, K. (2016). Exploration of the levels of mathematical proficiency displayed by grade 12 learners in responses to matric examinations. International Journal of Educational Sciences, 12(2), 231-246. https:/ / doi.org/10.1080/09751122.2016.11890457

Dunne, T., Long, C., Graig, T., \& Venter, E. (2012). Meeting the Requirements of both Classroom-Based and Systemic Assessment of Mathematics Proficiency: The Potential of Rasch Measurement Theory. Pythagoras, 33(3), Art. \#19, 16 pages. http:/ / doi.org/10.4102/pythagoras.v33i3.19

Eccles, P. J. (2007). An introduction to mathematical reasoning, numbers, sets and functions. New York, Cambridge University Press. Retrieved from https://www.maths.manchester.ac.uk/ nige/IMRpartI.pdf

Eppe, M., Maclean, E., Confalonieri, R., Kutz, O., Schorlemmer, M., Plaza, E., \& Kuhnberger, K. (2018). A computational framework for conceptual blending. Artificial Intelligence, 256, 105-129. https:// doi.org/10.1016/j.artint.2017.11.005

Fauconnier, G., \& Turner, M. (2002). The way we think: Conceptual blending and the mind's hidden complexities. New York, Basic Books. Retrieved from https://www.amazon.com/Way-We-Think-ConceptualComplexities/dp/0465087868

Figueiredo, C., Leite, C., \& Fernandes, P. (2016). The curriculum in school external evaluation frameworks in Portugal and England. Comparative $\mathcal{E}$ International Education, 11(3), 282-297. https:/ / doi.org/101177/1745499916661933

Foster, C. (2018). Developing mathematical fluency: Comparing exercises and rich tasks. Educational Studies in Mathematics, 97, 121-141. https:// doi.org/10.1007/s10649-017-9788-x

Fujita, T., Kondo, Y., Kumakura, H., \& Kunimune, S. (2017). Students' geometry thinking with cube representations: Assessment framework and empirical evidence. Journal of Mathematical Behavior, 46, 96-111. https:// doi.org/10.1016/j.jmathb.2017.03.003

Gerson, H., \& Walter, J. (2008). How blending illuminates understanding of calculus. In Electronic proceedings for the eleventh special interest group o the mathematical association of America on research in undergraduate mathematics. Retrieved from http:/ / rume.org/crume2008/Proceedings/Gerson\%20LONG.pdf

Gibbs, G. R. (2012). Different approaches to coding. Sociological Methodology, 42, 82-84. https:// doi.org/10.1177/0081175012460853

Gorard, S. (2005). The advantages of the mean deviation. British Journal of Educational Studies, 53(4), 417-430. https://doi.org/10.1111/j.1467-8527.2005.00304.x

Graven, M., \& Venkat, H. (2014). Primary teachers' experiences relating to the administration processes of highstakes testing: The case of mathematics annual national assessments. African Journal of Research in Mathematics, Science and Technology Education, 18(3), 299-310. Retrieved from https:/ / doi.org/10.1080/10288457.2014.965406

Hegarty, M., \& Waller, D. (2004). A dissociation between mental rotation and perspective-taking spatial abilities. Intelligence, 32, 175-191. https:/ / doi.org/10.1016/j.intell.2003.12.001

Heyd-Metzuyanim, E., Munter, C., \& Greeno, J. (2018). Conflicting frames: a case of misalignment between professional development efforts and a teacher's practice in a high school mathematics classroom. Educational Studies in Mathematics, 97, 21-37. https:/ / doi.org/10.1007/s10649-017-9777-0

Hombo, M. (2003). NAEP and No Child Left behind: Technical Challenges and Practical Solutions. Theory Into Practice, 42(1), 59-65. Retrieved from https:/ / www.jstor.org/stable/1477319 
Jonsson, B., Norqvist, M., Liljekvist, Y., \& Lithner, J. (2014). Learning mathematics through algorithmic and creative reasoning. The Journal of Mathematical Behavior, 36, 20-32. https:// doi.org/10.1016/j.jmathb.2014.08.003

Johnson, S. (2017). Design challenges for national assessment in this accountability era: A background paper commissioned by Cambridge Assessment. Cambridge, UK: Cambridge Assessment. Retrieved from http:/ / www.cambridgeassessment.org.uk

Kanjee, A., \& Moloi, Q. (2016). A standard-based approach for reporting assessment results in South Africa. Perspectives in Education, 34(4), 29-51. https:/ / doi.org/10.18820/2519593X/pie.v34i4.3

Kellaghan, T., Greaney, V., \& Murray, S. T. (2009). Using the results of a national assessment of educational achievement. Washington, DC, World Bank. Retrieved from http:/ / hdl.handle.net/10986/2667

Kilpatrick, J., Swafford, J., \& Findell, B. (2001). (Eds.). Adding it up: Helping children learn mathematics, Washington D.C: National Academy Press, 115-155. https:/ / doi.org/10.17226/9822

Klenowski, V., \& Wyatt-Smith, C. (2012). The impact of high stakes testing: the Australian story. Assessment in Education: Principles, Policy and Practice, 19(1), 65-79. https:/ / doi.org/10.1080/0969594X.2011.592972

Koichu, B., \& Leron, U. (2015). Proving as problem solving: The role of cognitive decoupling. The Journal of Mathematics Behavior, 40, 233-244. https:/ / doi.org/10.1016/j.jmathb.2015.10.005

Komatsu, K., Jones, K., Ikeda, T., \& Narazaki, A. (2017). Proof validation and modification in secondary school geometry. Journal of Mathematical Behavior, 47, 1-15. https:/ / doi.org/10.1016/j.jmathb.2014.07.002

Lachmy, R., \& Koichu, B. (2014). The interplay of empirical and deductive reasoning in proving 'if' and 'only if' statements in a dynamic geometry environment. Journal of Mathematical Behavior, 36, 150-165. https:// doi.org/10.1016/j.jmathb.2014.07.002

Lee, K. (2016). Students' proof schemes for mathematical proving and disproving of propositions. The Journal of Mathematical Behavior, 41, 26-44. https:// doi.org/10.1016/j.jmathb.2015.11.005

Lee, C. Y., \& Chen, M. J. (2015). Effects of worked examples using manipulatives on fifth graders' learning performance and attitude toward mathematics. Journal of Educational Technology E Society, 18(1), 264-275. Retrieved from http://www.jstor.org/stable/jeductechsoci.18.1.264

Lehrer, R. (2012). Longitudinal study of children's reasoning about space and geometry. In Designing learning environments for developing understanding of geometry and space (pp. 151-182). Routledge. Retrieved from https:/ / psycnet.apa.org/record/1998-06633-006

Long, C., \& Wendt, H. (2017). A comparative investigation of South Africa's high performing learners on selected TIMSS items comprising multiplicative concepts. African Journal of Research in Mathematics, Science and Technology Education, 21(2), 109-124. https:/ / doi.org/10.1080/18117295.2017.1306343

Mabotja, S., Chuene, K., Maoto, S., \& Kibirige, I. (2018). Tracking Grade 10 learners' geometric reasoning through folding back. Pythagoras, 39(1), a371. https:// doi.org/10.4102/ pythagoras.v39i1.371

Markovits, H., \& Doyon, C. (2011). Using analogy to improve abstract reasoning in adolescents: Not as easy as it looks. European Journal of Psychology of Education, 26(3), 355-372. https:/ / doi.org/10.1007/s10212-010-00541

Maoto, S., Masha, K., \& Mokwana, L. (2018). Teachers' learning and assessing of mathematical processes with emphasis on representations, reasoning and proof. Pythagoras, 39(1), https:/ / doi.org/10.4102/ pythagoras.v39i1.373

McHugh, M. L. (2012). Interrater reliability: The kappa statistic. Biochemia Medica, 22(3), $276-82$. https:/ / doi.org/10.11613/BM.2012.031

Munzer, S., Fehringer, B., \& Kuhl, F. T. (2018). Specificity of mental transformations involved in understanding spatial structures. Learning and Individual Differences, 61, 40-50. https:/ / doi.org/10.1016/j.lindif.2017.11.004

Otten, O., Bleiler-Baxter, S. K., \& Engledowl, C. (2017). Authority and whole-class proving in high school geometry: The case of Ms. Finley. The Journal of Mathematical Behavior, 46, 112-127. https:// doi.org/10.1016/j.jmathb.2017.04.002

Pedemonte, B., \& Balacheff, N. (2016). Establishing links between conceptions, argumentation and proof through the ck\$-enriched Toulmin Model. The Journal of Mathematical Behavior, 41,104-122. https:// doi.org/10.1016/j.jmathb.2015.10.008

Pittalis, M., \& Christou, C. (2010). Types of reasoning in 3D geometry thinking and their relation with spatial ability. Educational Studies in Mathematics, 75(2), 191-212. https:/ / doi.org/10.1007/s10649-010-9251-8

Pournara, C., Mpofu, S., \& Sanders, Y. (2015). The Grade 9 maths ANA - What can we see after three years? Learning and Teaching of Mathematics, 18, 34-41. Retrieved from https://hdl.handle.net/10520/EJC175718 
Resnick, B. L., \& Schantz, E. (2017). Testing, teaching, learning: who is in charge? Assessment in Education: Principles, Policy E Practice, 24(3), 424-432. https:/ / doi.org/10.1080/0969594X.2017.1336988

Spaull, N. (2016). Disentangling the language effect in South African schools: Measuring the impact of 'language of assessment' in Grade 3 literacy and numeracy. South African Journal of Childhood Education, 6(1). Retrieved from https:// doi.org/10.4102/ sajce.v6i.475

Sidney, P. G., \& Alibali, M. W. (2015). Making connections in math: Activating a prior knowledge analogue matters for learning. Journal of Cognition and Development, 16(1), 160-185. https:/ / doi.org/10.1080/15248372.2013.792091

Singh, K. (2007). "Quantitative social research methods" New Delhi: SAGE Publications. https:/ / doi.org/10.4135/9789351507741

Surtees, A., Apperly, I., \& Samson, D. (2013). Similarities and differences in visual and spatial perspective-taking processes. Cognition, 129, 426-438. https:// doi.org/10.1016/j.cognition.2013.06.008

Umugiraneza, O., Bansilal, S., \& North, D. (2018). Exploring teachers' descriptions of ways of working with the curriculum in teaching mathematics and statistics. African Journal of Research in Mathematics Science and Technology Education, 22(1), 70-80. https:/ / doi.org/10.1080/18117295.2018.1445496

Usiskin, Z. (1987). "Resolving the continuing dilemmas in school geometry". In M. M. Lindquist and A. P. Shulte (Eds), Learning and Teaching Geometry, K-12. Reston, VA, National Council of Teachers of Mathematics. Retrieved from https:/ / books.google.co.za/books?isbn=160752709X

Yazan, B. (2015). Three approaches to case study methods in education: Yin, Merriam, and Stake. The Qualitative Report, 20(2), 134-152. Retrieved from https:/ / nsuworks.nova.edu/tqr/vol20/iss2/12

Yin, R. K. (1984). Case study research: design and methods. Beverly Hills, Calif: Sage Publications. Retrieved from https:/ / evaluationcanada,ca/system/files/cjpe-entries/30-1-108.pdf

Yoon, C., Thomas, M. O. J., \& Dreyfus, T. (2011). Grounded blends and mathematical gesture spaces: Developing mathematical understanding via gestures. Educational Studies in Mathematics, 78, 371-393. https:/ / doi.org/10.1007/s10649-011-9329-y

Yopp, D. A. (2015). Prospective elementary teachers' claiming in responses to false generalizations. The Journal of Mathematical Behavior, 39, 79-99. https://doi.org/10.1016/j.jmathb.2015.06.003

Zandieh, M., Roh, K. H., \& Knapp, J. (2014). Conceptual blending: Student reasoning when proving "conditional implies conditional" statements. The Journal of Mathematical Behavior, 33, $209-229$. https:/ / doi.org/10.1016/j.jmathb.2013.11.007

\section{http://www.ejmste.com}

